\title{
Optimization of the CMP Process with Colloidal Silica Performance for Bulk AIN Single Crystal Substrate
}

\author{
Hyo Sang Kang ${ }^{1,3}$, Joo Hyung Lee ${ }^{1}$, Jae Hwa Park ${ }^{3}$, Hee Ae Lee', \\ Won II Park ${ }^{1}$, Seung Min $\mathrm{Kang}^{4}$, and Sung Chul $\mathrm{Yi}^{2}$,* \\ ${ }^{1}$ Department of Materials Science and Engineering, Hanyang University, Seoul 04763, Republic of Korea \\ ${ }^{2}$ Department of Chemical Engineering, Hanyang University, Seoul 04763, Republic of Korea \\ ${ }^{3}$ AMES Micron Co. LTD, Gimpo-si 10126, Republic of Korea \\ ${ }^{4}$ International Design Convergence Graduate School, Hanseo University, Seosan 31962, Republic of Korea
}

\begin{abstract}
Chemical mechanical polishing (CMP) of bulk AlN was performed with colloidal silica slurry at pH 9 for different times. The result shows that colloidal silica slurry at $\mathrm{pH} 9$, which has the relatively high surface charge of $-50.7 \mathrm{mV}$ is most stable. Thus, it was selected as chemically optimum condition in this study. The ultrasmooth surface was shown in CMP 90 min with the roughness average (Ra) value of $0.172 \mathrm{~nm}$. It was demonstrated that the damaged layers including subsurface defects and micro scratches in the whole machining process were successfully removed and atomically flat surface can be shown. With increasing process time, the zeta potential and mean particle size of the colloidal silica decreased and increased to $35.07 \mathrm{mV}$ and $143.4 \mathrm{~nm}$, respectively. While the silica particles agglomerated and densely packed slurry particles were formed by mechanical shearing, these increased the Ra value to above $0.5 \mathrm{~nm}$ of AlN substrate and generated additional surface damages. In terms of the surface chemistry, the carbon compounds and organic impurities adsorbed on the substrate during mechanical polishing (MP) can be removed and aluminum oxide-hydroxide; AlOOH and $\mathrm{Al}(\mathrm{OH})_{3}$ were observed during the CMP. It was determined that the chemically polished AlN substrate was continuously hydrated with generating the $\mathrm{AlOOH}$ and $\mathrm{Al}(\mathrm{OH})_{3}$ on the surface.
\end{abstract}

(Received June 4, 2019; Accepted July 15, 2019)

Keywords: aluminum nitride, chemical mechanical polishing, colloidal silica, material removal rate, surface chemistry, slurry agglomeration

\section{INTRODUCTION}

Group III-Nitride compound semiconductor substrates such as GaN, AlN, and InN are next-generation semiconductor materials that exhibit excellent features such as potential for miniaturization and light weight, low power consumption, and long lifetime of devices; demand for such material is steadily increasing [1,2]. Aluminum nitride (AIN), which has a wide bandgap of $6.2 \mathrm{eV}$, high thermal stability and thermal conductivity, and wide critical electric fields $(12.5 \mathrm{MV} / \mathrm{cm})$, has been applied to AlGaN-based ultraviolet optoelectronic devices; because it can provide superior power properties, it is used mainly as an substrate for various applications

- 강효상·이주형·이희애: 박사과정, 박재화: 연구소장, 박원일·강승민·이성철: 교수 *Corresponding Author: Sung Chul Yi

[Tel: +82-2-2220-0481, E-mail: scyi@hanyang.ac.kr]

Copyright (C) The Korean Institute of Metals and Materials ranging from semiconductor devices to laser diodes (LD) and light emitting diodes (LED) [3-5].

In order to apply AIN single crystal substrates to such applications, ultra-smooth, atomically flat and defect-free the substrate surfaces are required. However, bulk AlN single crystals are difficult to manufacture due to their high hardness and chemical inertness $[3,6]$. In particular, the poor surface morphology and micro-defects inherent in the sub-surface of the substrate are the main sources of degradation of device performance, generating consecutive defects of the epitaxial layer grown on native substrates [7,8]. Therefore, to increase the potential performance of the material, it is essential to obtain high optical quality and defect-free substrate surfaces [9-11].

CMP is the most effective technique for obtaining an ultrasmooth undamaged surface of a substrate in a semiconductor process. CMP simultaneously physically and chemically smooths the surface of the substrate; it also removes damaged 
layers generated by MP on the surface and sub-surface of the substrate $[1,3,6]$. The principle of CMP is to push down a slurry containing both abrasive and reactive chemicals while simultaneously rotating the pads and the wafer in the opposite direction. The water $\left(\mathrm{H}_{2} \mathrm{O}\right)$ molecules in the slurry penetrate the atomic bonds of the wafer surface and form an oxide layer, and this reduces the hardness of the wafer. The lower-hardness wafer surface is polished by the physical friction of the rotating platen $[12,13]$. The abrasive used in the slurry should be harder than the mixture produced in the process, but it should be softer than the substrate and should be selected for its ability to easily remove the mixture during post-cleaning $[1,13]$.

The most typical materials used as abrasives for CMP slurries are silica, ceria, and alumina; they are used differently according to the properties of the material when processing semiconductor substrates. Ceria and alumina have selectivity and material removal rate (MRR) for chemical additives relatively higher than those values of silica, but it is hard to manipulate surface scratches and perform post cleaning When using ceria and alumina [6,14]. Silica has a relatively low MRR; however, it has high dispersibility and uniformity of particles, and it has been applied mainly to the processing of semiconductor substrates to obtain defect-free surfaces on substrates. The colloidal silica slurry has been mainly used for group III-nitride single crystals; studies on the composition of this material have been actively carried out until now $[1,6,14]$. Although the silica slurry has relatively high surface charge and repulsive force between particles, it can also agglomerate of silica particles by manipulating extrinsic variables; shear rate, process time and $\mathrm{pH}$ etc. during CMP [15].

The agglomeration of silica particles can increase the surface roughness and number of defects of the polished substrate. This performance used mainly to occur when CMP was conducted in ambient air, due to the inherent characteristics of silica slurry [15-17]. Hence, in order to prevent additional defects from agglomerated particles, optimum process conditions must be determined.

In this study, CMP using colloidal silica at $\mathrm{pH} 9$ was performed for different times to obtain optimum conditions for fabrication of an AlN substrate. The MRR and zeta potential of colloidal silica with different $\mathrm{pH}$ were analyzed to confirm the most stable conditions of colloidal silica. The surface characteristics were characterized by atomic force microscopy (AFM) and zeta potential and particle size analyzer. In order to determine the extent of damaged layer and chemical changes on the AIN substrate surface, X-ray photoelectron spectroscopy (XPS) were performed.

\section{EXPERIMENTAL PROCEDURES}

Bulk AlN single crystal wafers grown by physical vapor transport (PVT) with characteristics of 2-inch width, $870 \mu \mathrm{m}$ thickness, and c-plane (0001) were prepared, while double side MP was conducted with water soluble diamond slurry; the final Ra values of the mechanically polished wafers were less than $0.5 \mathrm{~nm}$. The $\mathrm{pH}$ of the colloidal silica slurry was manipulated by $35 \% \mathrm{HNO}_{3}$ solution. The zeta potential of colloidal silica was analyzed using a zeta potential and particle size analyzer (Otsuka Electronics, ELSZ-1000, Japan), and the MRR for the AIN single crystal (al-polar face) were characterized using an electronic balance (Ohaus, E02130, USA), which has an accuracy of $0.0001 \mathrm{~g}$ according to the weight loss, and Equation (1), used to calculate the MRR is as follows [11,14]:

$$
\operatorname{MRR}=\Delta \mathrm{m} /\left(\rho \times r^{2} \times t\right)
$$

$\Delta \mathrm{m}(\mathrm{g})$ is the removal mass of material, $\rho\left(\mathrm{g} / \mathrm{cm}^{3}\right)$ is the density of $\mathrm{AlN}, \mathrm{r}(\mathrm{cm})$ is the radius of the wafer, and $\mathrm{t}(\mathrm{hr})$ is the polishing time. The CMP was conducted on an EK-3801D machine with colloidal silica slurry at $\mathrm{pH} 9$ and a SUBA-600 pad. The morphology and particle size of the colloidal silica at $\mathrm{pH} 9$ were obtained for scanning electron microscope (SEM-Jeol, JSM5900LV, Japan), and particle size distribution at $\mathrm{pH} 9$ was characterized using a zeta potential and particle size analyzer (Otsuka Electronics, ELSZ-1000, Japan). The CMP conditioner was used to manipulate the distribution of the slurry and the roughness of the pad; detailed CMP conditions are shown in Table 1. After CMP has been performed several times, aspolished wafers were rinsed ultrasonically with acetone, ethanol, and deionized water for 15 minutes each; wafers were then dried using pure $\mathrm{N}_{2}$. The surface morphology and roughness were determined using AFM (PSIA, XE-100, Korea); zeta potential and mean particle size with increasing process time were characterized using a zeta potential and particle size analyzer (Otsuka Electronics, ELSZ-1000, Japan). Chemical changes on the polished surfaces using MP to CMP were analyzed via XPS 
Table 1. AIN CMP process condition.

\begin{tabular}{lcc}
\hline \multicolumn{1}{c}{ Name } & Unit & Quantity \\
\hline Platen rotation speed & $\mathrm{RPM}$ & 25 \\
\hline Carrier rotation speed & $\mathrm{RPM}$ & 25 \\
\hline Applied pressure & $\mathrm{kg} / \mathrm{cm}^{2}$ & 0.03 \\
\hline Feed rate of the slurry & $\mathrm{ml} / \mathrm{min}$ & 35 \\
\hline Diameter of plate & $\mathrm{mm}$ & 110 \\
\hline Polishing pad type & - & Suba-600 \\
\hline Abrasive particle & - & Silica \\
\hline Particle concentration & $\%$ & 30 \\
\hline pH & - & 9.02 \\
\hline Polishing time & $\mathrm{min}$ & $30-150$
\end{tabular}

(Thermo scientific, theta probe base system, USA).

\section{RESULTS AND DISCUSSION}

\subsection{Performance of the colloidal silica slurry}

The MRR and zeta potential of the colloidal silica slurry with different $\mathrm{pH}$ were characterized as shown in Fig. 1. Zeta potential is a function of electrostatic interactions, which are generated between the wafer and particles. The zeta potential of colloidal silica was negatively charged overall and it gradually increased from -14.5 to $-50.70 \mathrm{mV}$ as the $\mathrm{pH}$ increased from $\mathrm{pH} 4$ to 9 . In acidic conditions, the colloidal silica particles with relatively low surface charge could be easily adsorbed to the wafer surface and hinder the performance of oxidants during CMP. With decreasing $\mathrm{pH}$, the MRR also reached the highest value $(14.2 \mathrm{~nm} / \mathrm{h})$ at $\mathrm{pH} 5$ and decreased rapidly to $6.0 \mathrm{~nm} / \mathrm{h}$ at $\mathrm{pH} 10$, this can show that the acid condition is suitable to obtain high MRR than base condition but it can easily cause the agglomeration of silica particles. Thus, colloidal silica in base condition is more suitable to obtain defect-free surface. However, when it was conducted with colloidal silica slurry above the particular process time, physical effects were dominant than chemical effects for colloidal silica slurry. Thus, the colloidal silica at $\mathrm{pH} 9$ which has the highest zeta potential value was selected; morphology, particle size, and particle size distribution were characterized as shown in Fig. 2. The CMP with colloidal silica at $\mathrm{pH} 9$ was performed for different times to investigate physical effects for AIN substrates in detail.

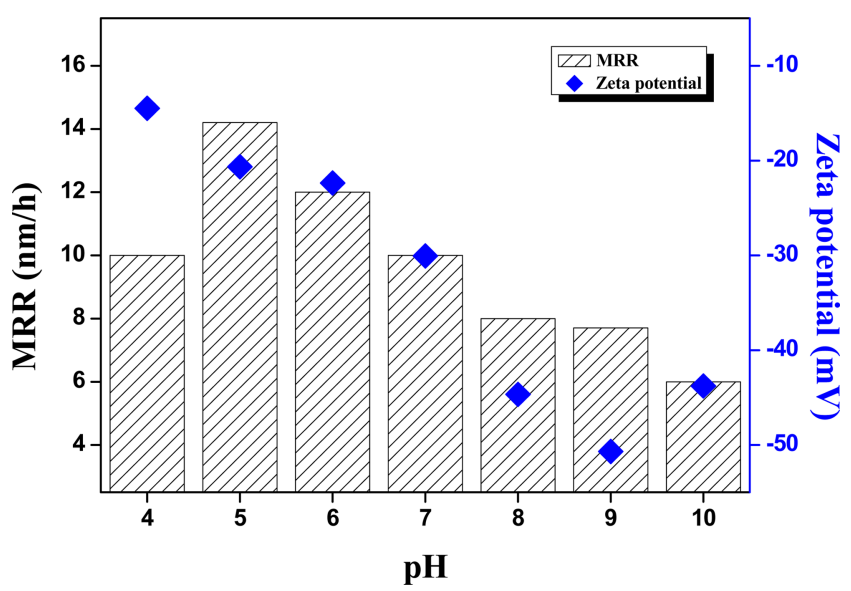

Fig. 1. MRR and zeta potential of the colloidal silica slurry with different $\mathrm{pH}$.
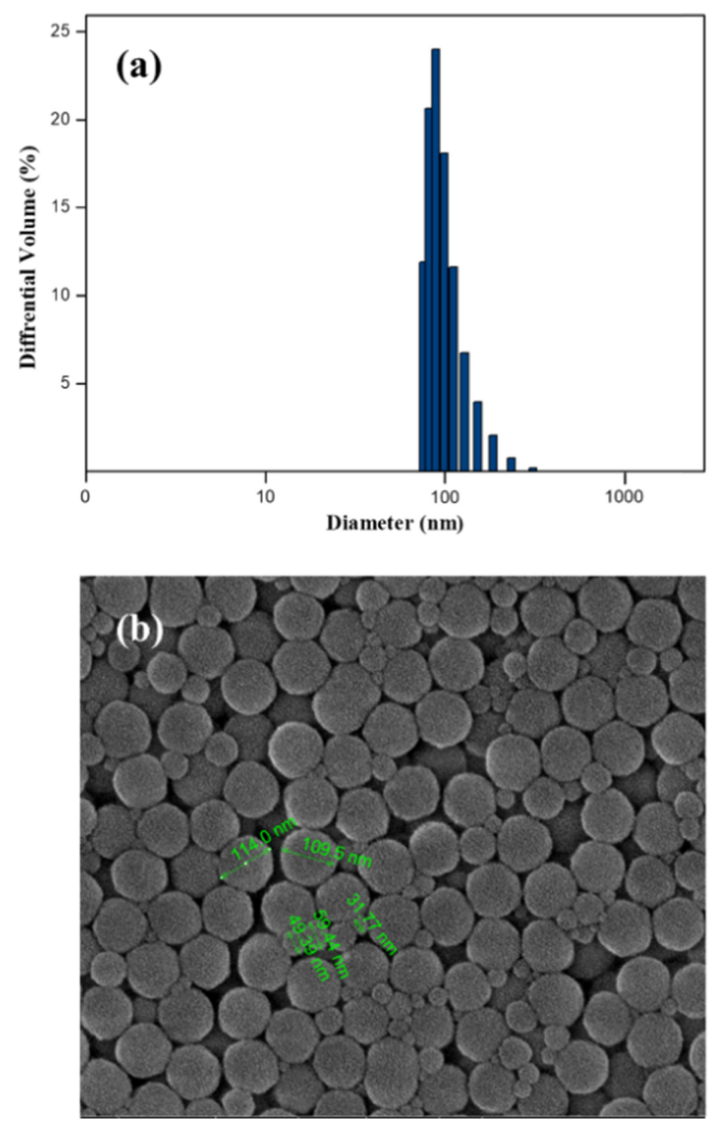

Fig. 2. (a) Particle size distribution of colloidal silica slurry at pH 9 and (b) SEM image of colloidal silica particles.

\subsection{Polished surface morphology analysis}

Figure 3 shows the surface roughness and surface morphology according to time during CMP. In Fig. 3 (a), several defects including micro scratches and irregular pull- 


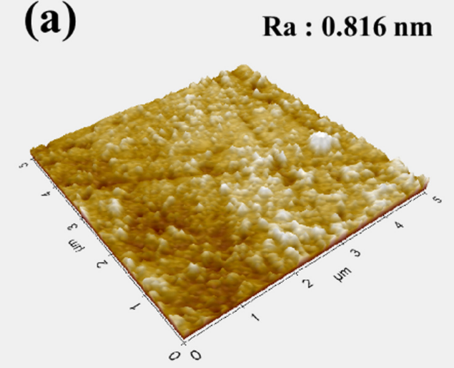

(d)

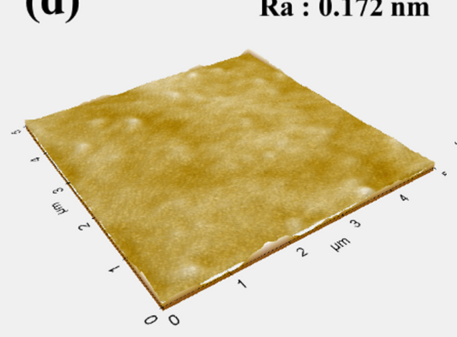

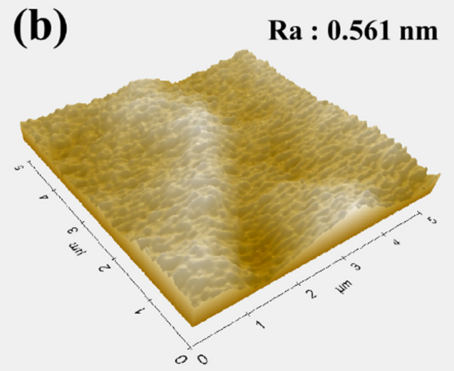

(e)

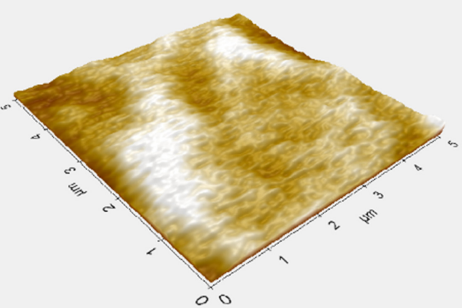

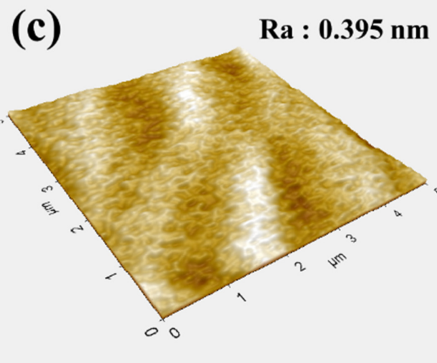

(f)

$\mathrm{Ra}: 0.670 \mathrm{~nm}$

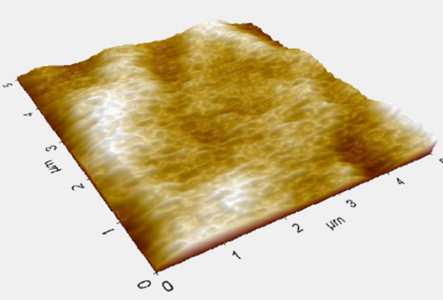

Fig. 3. AFM images of AIN surface after each CMP process. (a) after MP, (b) CMP 30 min, (c) CMP 60 min, (d) CMP 90 min, (e) CMP 120 min, (f) CMP 150 min.

outs can be observed on the surface despite the low surface roughness of $1 \mathrm{~nm}$ or less after MP; residue of the diamond slurry adsorbed on the surface can also be observed. In Fig. 3 (b), defects such as micro-scratches and pull-out phenomena generated on the surface were successfully removed using the colloidal silica slurry, and the surface roughness decreased. However, the damaged layers were not completely removed during MP, and an additional process of 60-150 min was performed to reduce the remaining damaged layer. Figure 3 (c) shows the significantly lower and smooth surface properties with $\mathrm{Ra} 0.395 \mathrm{~nm}$, but some damaged layers remained on the surface. Figure 3 (d) shows an ultra-smooth surface roughness and shape with $\mathrm{Ra}$ of $0.172 \mathrm{~nm}$ that the remaining damaged layer on the surface was completely removed. However, in Fig. 3 (e) and Fig. 3 (f), it is confirmed that the Ra value gradually increased from 0.537 to $0.670 \mathrm{~nm}$, and the surface morphology was also uneven. It was considered that agglomeration of the slurry particles occurred and increased due to the continuous mechanical stress and interaction of local particles generated during CMP. Thus, after a certain period of CMP, the slurry particles became harder, the average particle size of the slurry increased, and the slurry became non-uniform. In order to characterize the detailed mechanism of the interaction between colloidal silica particles during CMP, particle size distribution and zeta potential were analyzed; results are explained in Fig. 4.

\subsection{Particle size distribution and zeta potential analysis}

Figure 4 shows the average particle size distribution and zeta potential value of the colloidal slurry with process time. From the initial state of process to CMP $60 \mathrm{~min}$, a particle size of about 120.8-121.2 nm was observed. After CMP 60 $\mathrm{min}$, the particle size increased significantly from $121.2 \mathrm{~nm}$ to $143.4 \mathrm{~nm}$. While the particle size greatly increased, the zeta potential gradually decreased about from $-56.94 \mathrm{mV}$ to $-35.07 \mathrm{mV}$. The lower zeta potential indicates lower surface charges of the silica particles, with decreasing repulsive forces of particles and increasing coarsening of the particles; the coarsened particles formed particle agglomerates. While mechanical shearing reduced many of the soft particle agglomerates, it broke weak inter-particle interactions by van der Waals forces during CMP and formed more densely packed particles. These processes occurred simultaneously but formation of the densely packed particles was predominantly generated, and it changed the particle size distribution with increasing process time. This result implies that agglomerated particles caused other micro-defects on the polished surface, 


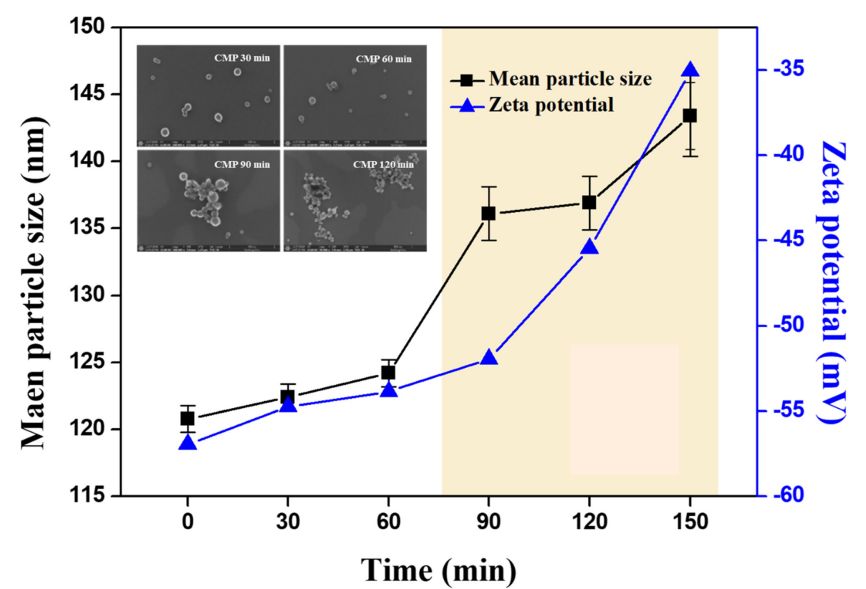

Fig. 4. Mean particle size and zeta potential of silica slurry for different times.

and increased the Ra value [15-18]. Thus, in order to inhibit the formation of additional damage on the surface, it is essential to determine the time when slurry particles change and agglomerate with increasing process time.

\subsection{XPS analysis of polished surface}

The XPS analysis was performed to assess the surface chemistry as shown in Fig. 5. This presents a survey scan graph that identifies the chemical composition and elements present on the surface. The graph shows a typical spectrum obtained from XPS analysis, of a polished AIN single crystal after MP and CMP. The photoelectron peaks represent $\mathrm{Al} 2 \mathrm{~s}$, $\mathrm{Al} 2 \mathrm{p}$, and N1s, which are the core level peaks of AlN; O1s and $\mathrm{C} 1 \mathrm{~s}$ peaks were observed in the other peaks. As a result of the chemical composition changes induced by MP and $\mathrm{CMP}$, the intensity of the peaks at $\mathrm{C} 1 \mathrm{~s}$ and $\mathrm{O} 1 \mathrm{~s}$ rapidly decreased after CMP, and $\mathrm{Al}$ and $\mathrm{N}$ decreased slightly. In order to analyze in detail the changes of the core level spectra of each element, a high resolution (HD) scan was performed and results were analyzed for MP and CMP for each condition. In the case of $\mathrm{C} 1 \mathrm{~s}$, however, when the specimens were measured, the carbonated compounds present in air were also detected. For this reason, since the reliability of the component analysis was poor, results were excluded from the precision analysis in the HD scan [19].

Figure 6 shows the $\mathrm{O} 1 \mathrm{~s}$ spectra. $\mathrm{O}^{2-}$ and $\mathrm{OH}^{-}$peaks ranging from 530.7 to $532.3 \mathrm{eV}$ represent aluminum trihydroxide $\left(\mathrm{Al}(\mathrm{OH})_{3}\right)$, monohydrated alumina $(\mathrm{AlOOH})$, or aluminum oxide $\left(\mathrm{Al}_{2} \mathrm{O}_{3}\right)$ depending on the composition ratio of each

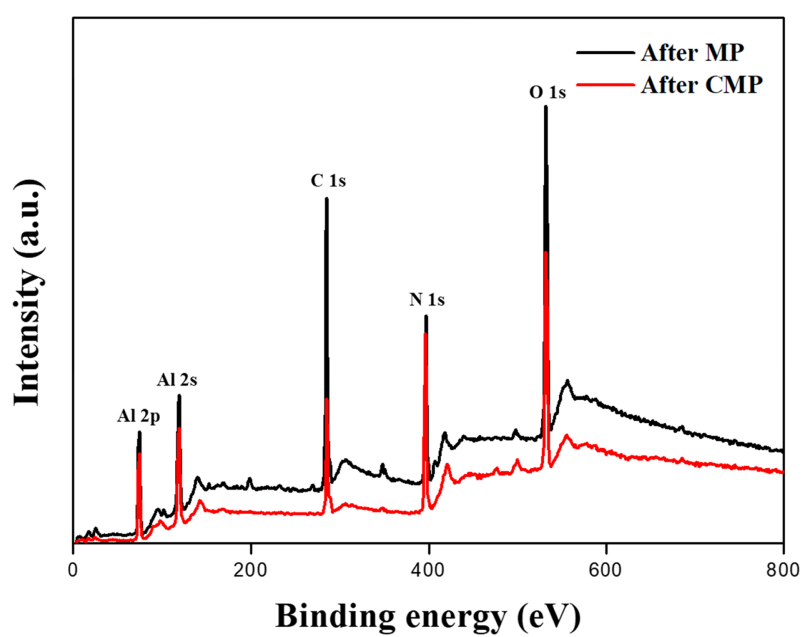

Fig. 5. Survey scans after MP and CMP.

compound $\left(\mathrm{Al}_{2} \mathrm{O}_{3} \cdot \mathrm{xH}_{2} \mathrm{O}\right)[8,19,20]$. From MP to CMP $90 \mathrm{~min}$, the intensity of the hydroxide peak rapidly decreased to less than half its original level, and the oxide peak also was shown to have a relatively broad graph. After CMP $90 \mathrm{~min}$, both peaks were maintained to constant levels of intensity and the binding energy decreased by about $0.3 \mathrm{eV}$. It was demonstrated that MP was performed with a water soluble diamond slurry for a stepwise polishing process in ambient air; continuous oxidization and hydration occurred on the surface of the single crystal. Since external oxygen and $\mathrm{H}_{2} \mathrm{O}$ combined with elemental aluminum, the reaction produced aluminum oxidehydroxide compounds while replacing elemental nitrogen as indicated by Equation (2), as follows [1]:

$$
\begin{aligned}
& \mathrm{AlN}+2 \mathrm{H}_{2} \mathrm{O} \rightarrow \mathrm{AlOOH}+\mathrm{NH}_{3} \\
& \mathrm{AlOOH}+\mathrm{H}_{2} \mathrm{O} \rightarrow \mathrm{Al}(\mathrm{OH})_{3}
\end{aligned}
$$

It was determined that the $\mathrm{AlOOH}$ (peak: $531.5 \mathrm{eV}$ ) that occurred on the surface was removed during CMP and that $\mathrm{AlOOH}$ adsorbed on the surface was hydrated continuously, generating a small amount of $\mathrm{Al}(\mathrm{OH})_{3}$ (peak: $531.3 \mathrm{eV}$ ).

Figure 7 shows the Al2p spectra. The Al-O bond ranging from 74.3 to $75.1 \mathrm{eV}$ represents $\mathrm{AlOOH}$ or $\mathrm{Al}(\mathrm{OH})_{3}$; the $\mathrm{Al}-\mathrm{N}$ bond is in the range of 73.2 to $73.8 \mathrm{eV}[20,21]$. The intensity of the $\mathrm{AlOOH}$ peak decreased by one third after CMP $30 \mathrm{~min}$, and the intensity of the Al-N peak increased slightly. From CMP 60 min, the intensity of the Al-O peak increased slightly and the binding energy decreased by about $0.5 \mathrm{eV}$. After that, 


\section{O1s scan}

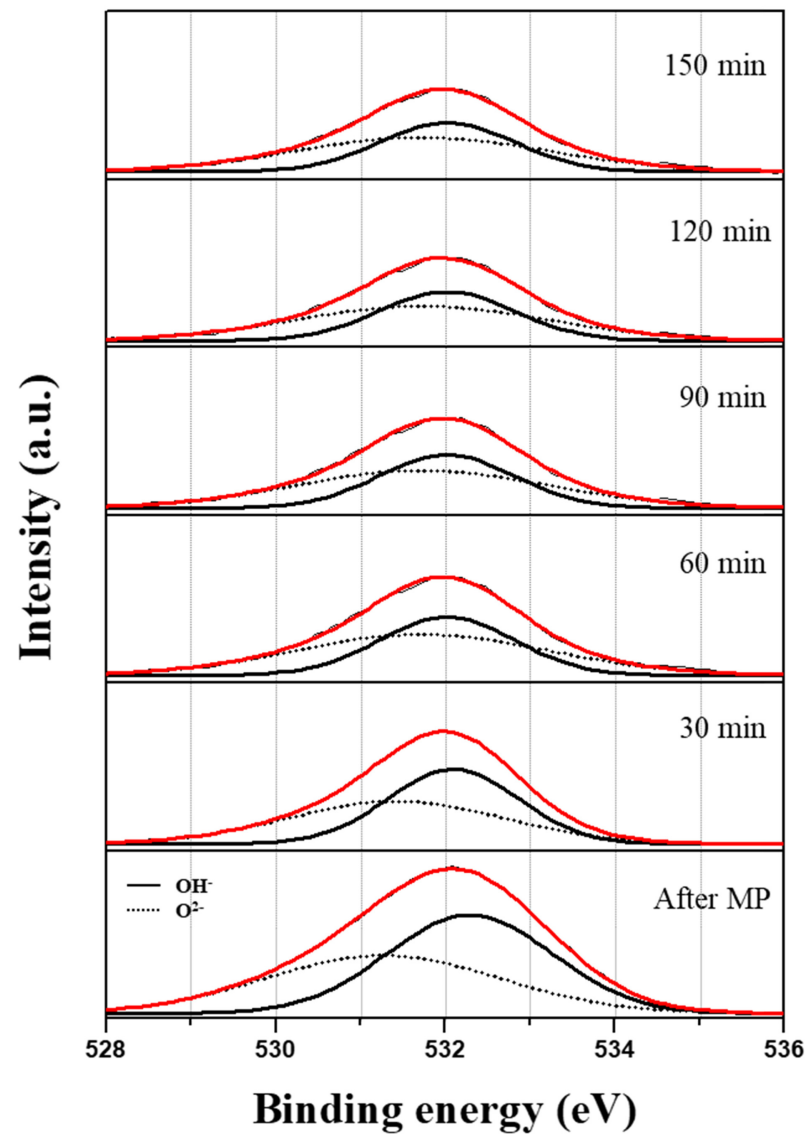

Fig. 6. Binding energies of core level of O1s scan.

the intensity of the Al-O peak was sustained at a constant level. As shown in Fig. 6, the $\mathrm{AlOOH}$ generated on the surface during MP was removed through CMP and the relative density of Al$\mathrm{N}$ on the surface increased.

Figure 8 shows the N1s spectra. The N-C bond is in the range of about 397.7-398.4 eV and the N-Al bond is in the range of about $396.1 \mathrm{eV}-396.7 \mathrm{eV}$ [20, 22]. After MP, the intensity of the N-C bond (peak: $398.4 \mathrm{eV}$ ) gradually decreased until CMP 150 min, and the N-Al bond (peak: $396.4 \mathrm{eV}$ ) was maintained at a similar intensity. This shows that the nitrogen-carbon compound from the diamond slurry in the MP had been removed.

\section{CONCLUSION}

Bulk AlN single crystals were subjected to CMP using colloidal silica slurry at $\mathrm{pH} 9$ for different times; performance of

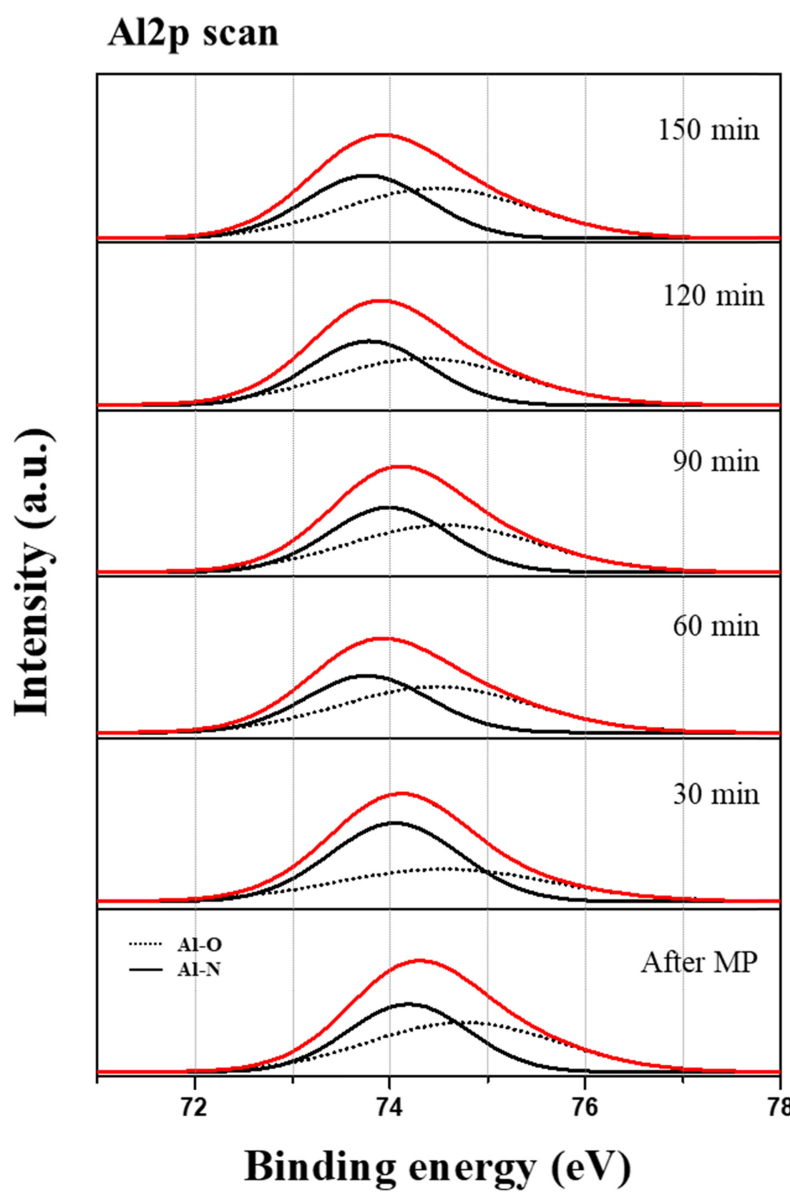

Fig. 7. Binding energies of core level of Al2p scan.

the colloidal silica slurry, surface characteristics and chemical changes on the surface were characterized. The whole damaged layer was successfully removed, and an ultra-smooth surface, with the lowest possible surface roughness (Ra : $0.172 \mathrm{~nm}$ ), was obtained at CMP $90 \mathrm{~min}$; this surface was not much affected by agglomeration of colloidal silica slurry particles. While CMP was performed with silica slurry, mechanical shearing can decrease the number of soft agglomerates; however, mechanical shearing can break also weak interparticle interaction by van der Waals forces, and this seems to form more densely packed particles, which can increase a Ra value and generate additional damages on the surface. The XPS analysis was performed and, it was determined that an aluminum oxide-hydroxide compound was formed, while replacing nitrogen which was bonded to elemental aluminum with external oxygen and $\mathrm{H}_{2} \mathrm{O}$. The $\mathrm{AlOOH}$ adsorbed on the surface was removed during $\mathrm{CMP}$ and the $\mathrm{AlOOH}$ was 


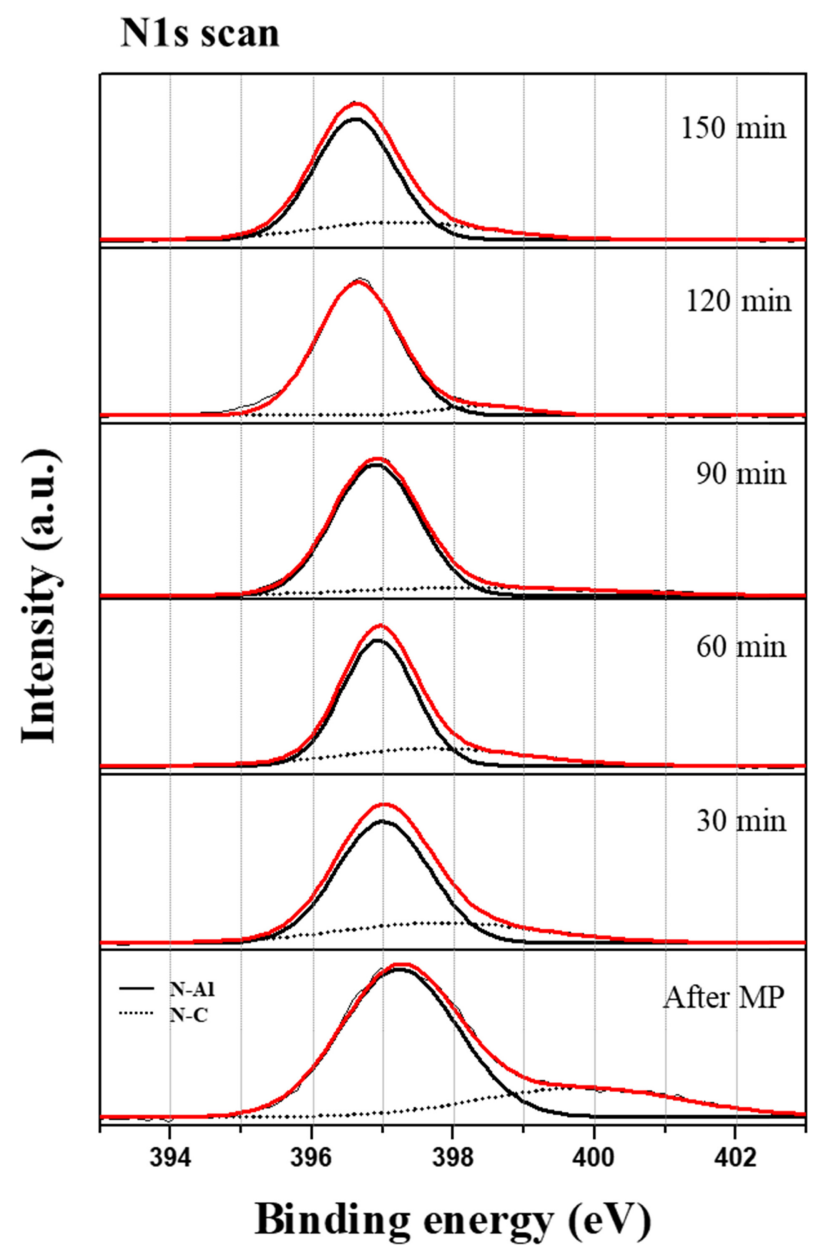

Fig. 8. Binding energies of core level of N1s scan.

hydrated continuously, generating a small amount of $\mathrm{Al}(\mathrm{OH})_{3}$. It was determined that the optimum process time to minimize the occurrence of additional defects and damaged layers on the surface was CMP 90 min.

\section{ACKNOWLEDGEMENT}

This work was supported by the Industrial Strategic Technology Development program funded by the Ministry of Trade Industry \& Energy, KOREA (Project No. 10043791).

\section{REFERENCES}

1. G. Slack, S. Schujman, N. Meyer, and L. Schowalter, US Patent No. 20060288929A1 (2006).

2. P. Reddy, I. Bryan, Z. Bryan, W. Guo, L. Hussey, R. Collazo, and Z. Sitar, J. Appl. Phys. 116, 123701 (2014).
3. K. Asghar and D. Das, J. Semicond. 37, 036001 (2016).

4. R. Dalmau, H. Craft, J. Britt, E. Paisley, B. Moody, J. Guo, Y. Ji, B. Raghothamachar, M. Dudley, and R. Schlesser, Mater. Sci. Forum, Trans. Tech. Publications, p. 923, Switzerland (2018).

5. P. Reddy, S. Washiyama, F. Kaess, M. Breckenridge, L. H. Balderrama, B. B. Haidet, D. Alden, A. Franke, B. Sarkar, E. Kohn, R. Collazo, and Z. Sitar, J. Appl. Phys. 119, 145702 (2016).

6. G. Chen, Z. Ni, L. Xu, Q. Li, and Y. Zhao, Appl. Surf. Sci. 359, 664 (2015).

7. X. F. Chen, D. Siche, M. Albrecht, C. Hartmann, J. Wollweber, and X. G. Xu, Cryst. Res. Technol. 43, 651 (2008).

8. A. Rice, R. Collazo, J. Tweedie, R. Dalmau, S. Mita, J. Xie, and Z. Sitar, J. Appl. Phys. 108, 043510 (2010).

9. X. Shi, G. Pan, Y. Zhou, L. Xu, C. Zou, and H. Gong, Surf. Coat. Technol. 270, 206 (2015).

10. J. Wang, T. Wang, G. Pan, and X. Lu, ECS J. Solid State Sci. Technol. 4, 112 (2015).

11. J. Wang, T. Wang, G. Pan, and X. Lu, Appl. Surf. Sci. 361, 18 (2016).

12. J. H. Lee, C. W. Park, J. H. Park, H. S. Kang, S. H. Kang, H. A. Lee, J. H. Lee, J. H. In, S. M. Kang, and K. B. Shim, J. Korean Cryst. Growth Cryst. Technol. 28, 51 (2018).

13. J. Chunrong and Z. Baoguo, 2015 Int. Conference on Planarization/CMP Technology (ICPT), p. 1, USA (2015).

14. Y. Zhou, G. Pan, H. Gong, X. Shi, and C. Zou, Colloids Surf. A Physicochem. Eng. Asp. 513, 153 (2017).

15. A. Sorooshian, R. Ashwani, H.K. Choi, M. Moinpour, A. Oehler, A. Tregub, Mater. Res. Soc. Symp. Proc. 816, (2011).

16. G. B. Basim and B. M. Moudgil, J. Colloid Interface Sci. 256, 137 (2002).

17. J. M. Johnson and D. Boning, G. S. Kim, P. Safier, and K. Knutson, Mater. Res. Soc. Symp. Proc. 1249 (2011).

18. A. J. Khanna, S. Gupta, P. Kumar, F. C. Chang, and R. K. Singh, ECS J. Solid State Sci. Technol. 7, 238 (2018).

19. I. Bryan, C.-R. Akouala, J. Tweedie, Z. Bryan, A. Rice, R. Kirste, R. Collazo, and Z. Sitar, Phys. Status Solidi. C 11, 454 (2014).

20. R. Dalmau, R. Collazo, S. Mita, and Z. SITAR, J. Electron. Mater. 36, 414 (2007).

21. L. Rosenberger, R. Baird, E. McCullen, G. Auner, and G. Shreve, Surf. Interface Anal. 40, 1254 (2008).

22. J. A. P. Taborda, H. R. Landazuri, and L. P. Vera, IEEE Sens. J. 16, 359 (2016). 